\title{
Análise experimental da resistência à tração de fios de sutura utilizados em
}

\section{Odontologia}

\author{
Experimental analysis of the tensile strength of suture threads used in Dentistry \\ Análisis experimental de la resistencia a la tracción de los hilos de sutura utilizados en Odontología
}

Recebido: 29/10/2021 | Revisado: 07/11/2021 | Aceito: 13/11/2021 | Publicado: 21/11/2021

\author{
Izadora Cunha Faria \\ ORCID: https://orcid.org/0000-0003-0620-9940 \\ Centro Universitário de Patos de Minas, Brasil \\ E-mail: izadoracfaria@unipam.edu.br \\ Helvécio Marangon Júnior \\ ORCID: https://orcid.org/0000-0002-9709-6795 \\ Centro Universitário de Patos de Minas, Brasil \\ E-mail:helveciomjr@unipam.edu.br \\ Rafael Martins Afonso Pereira \\ ORCID: https://orcid.org/0000-0002-1085-0813 \\ Centro Universitário de Patos de Minas, Brasil \\ E-mail: rafaelmap@unipam.edu.br \\ Rodrigo Soares de Andrade \\ ORCID: https://orcid.org/0000-0001-6114-0929 \\ Centro Universitário de Patos de Minas, Brasil \\ E-mail: rodrigosa@unipam.edu.br \\ Victor Henrique da Cunha Faria \\ ORCID: https://orcid.org/0000-0003-0063-6319 \\ Universidade Federal de Uberlândia, Brasil \\ E-mail:victorhcf@ufu.br \\ Rafaela Vargas e Silva \\ ORCID: https://orcid.org/0000-0002-9366-6332 \\ Centro Universitário de Patos de Minas, Brasil \\ E-mail: rafaelavargas@unipam.edu.nr
}

\begin{abstract}
Resumo
Diferentes calibres e composições de fios de sutura são encontrados no comércio. A sutura realizada de forma correta, respeitando-se as propriedades mecânicas dos fios como a resistência à tração e calibre adequado, gera um ambiente propício para a hemostasia e a reparação tecidual. Este estudo teve por objetivo avaliar a resistência à tração dos fios de sutura mais utilizados em odontologia por meio de pesquisa bibliográfica, experimental, descritiva, de abordagem quantitativa, com tabulação e análise sistemática de dados. A amostra desse experimento foi constituída de 25 fios que foram divididos em cinco grupos experimentais, levando-se em consideração a composição e o calibre. A avaliação quantitativa da resistência à tração e deformação dos fios de sutura foi realizada por meio de uma prensa universal da marca EMIC com sistema operacional INSTRON. As variáveis cardinais, obtidas pela mensuração de força e deformação, foram avaliadas por meio de estatística analítica para comparação de grupos. Dentre os resultados encontrados, o fio de Nylon 3.0 mostrou-se o mais resistente entre os corpos de prova, com força média de $29,08 \mathrm{~N}$ e deformação média de 40,58 mm. Constatou-se que em relação à força e à deformação, os fios de Nylon são mais resistentes à tração do que os de Seda. Em relação à força e ao calibre, os fios com maior diâmetro apresentaram maior resistência à tração, especialmente os fios de Nylon. Já em relação à deformação e ao calibre, não houve diferença estatística quando fios de sutura do mesmo material forma comparados.
\end{abstract}

Palavras-chave: Suturas; Resistência; Tração e deformação.

\begin{abstract}
Different calibers and compositions of suture threads are found in commerce. A correctly performed suture, respecting the suture's mechanical properties, such as tensile strength and adequate gauge, generates a favorable environment for hemostasis and tissue repair. The aim of this study was to evaluate the tensile strength of the most commonly used suture threads in dentistry through bibliographic, experimental, descriptive, and quantitative research, with systematic data tabulation and analysis. The sample of this experiment consisted of 25 threads that were divided into five experimental groups, taking into consideration their composition and caliber. Quantitative evaluation of tensile strength and deformation of suture threads was performed using an EMIC universal press with INSTRON operating system. The cardinal variables, obtained by measuring strength and deformation, were evaluated by analytical statistics for comparison of groups. Among the results found, the Nylon 3.0 wire proved to be the most resistant among the
\end{abstract}


specimens, with an average force of $29.08 \mathrm{~N}$ and average deformation of $40.58 \mathrm{~mm}$. It was found that in relation to strength and deformation, Nylon yarns are more resistant to traction than Silk yarns. Regarding strength and gauge, the yarns with larger diameter showed higher tensile strength, especially Nylon yarns. Regarding deformation and gauge, there was no statistical difference when suture threads of the same material were compared.

Keywords: Sutures; Strength; Tensile e deformation.

\section{Resumen}

Existen diferentes calibres y composiciones de hilos de sutura en el mercado. Una sutura correctamente realizada, respetando las propiedades mecánicas de los hilos, como la resistencia a la tracción y el calibre adecuado, genera un entorno favorable para la hemostasia y la reparación de los tejidos. El objetivo de este estudio fue evaluar la resistencia a la tracción de los hilos de sutura más utilizados en odontología mediante una investigación bibliográfica, experimental, descriptiva y cuantitativa, con tabulación y análisis sistemático de datos. La muestra de este experimento consistió en 25 hilos que se dividieron en cinco grupos experimentales, teniendo en cuenta la composición y el calibre. La evaluación cuantitativa de la resistencia a la tracción y la deformación de los hilos de sutura se realizó utilizando una prensa universal EMIC con el sistema operativo INSTRON. Las variables cardinales, obtenidas mediante la medición de la resistencia y la deformación, se evaluaron mediante estadísticas analíticas para comparar los grupos. Entre los resultados encontrados, el alambre de Nylon 3.0 resultó ser el más resistente entre las probetas, con una fuerza media de 29,08 N y una deformación media de 40,58 mm. Se ha comprobado que, en relación con la fuerza y la deformación, los hilos de nailon son más resistentes a la tracción que los de seda. En cuanto a la resistencia y la galga, los hilos de mayor diámetro presentaron una mayor resistencia a la tracción, especialmente los hilos de nailon. En cuanto a la deformación y el calibre, no hubo diferencias estadísticas cuando se compararon hilos de sutura del mismo material.

Palabras clave: Suturas; Resistencia; Tracción e deformación.

\section{Introdução}

A abertura de uma ferida, seja ela cirúrgica ou traumática, necessita da aproximação dos tecidos, por meio de suturas, para que haja o controle de sangramento e posterior reparação. O principal objetivo da sutura é aproximar e proteger as bordas dos retalhos, colocando-as em aposição, até que a reparação tenha sido suficiente para suportar as tensões funcionais, sendo o fio de sutura, o material mais utilizado para essa finalidade nas cirurgias odontológicas (Shaw; Negus; \& Mellor, 1996; Kurtzman, 2010). Quando a sutura é realizada de forma correta, respeitando-se as propriedades mecânicas e indicações de cada fio, é gerado um ambiente propício para hemostasia e reparação (Silverstein; Kurtzman; \& Shatz, 2009).

Dentre as qualidades que os fios de sutura necessitam ter, destaca-se a resistência à tração, propriedade esta que pode variar de acordo com as características do material selecionado. A United States Pharmacopeia (USP) define resistência a tração como a quantidade de força necessária para que haja a ruptura do fio dividida por sua área transversal. A resistência efetiva à tração é uma medida adicional para calcular a resistência de fios de sutura que tenham nós atados (Bennet, 1988). No Brasil, os fios de sutura são padronizados pela Associação Brasileira de Normas Técnicas (ABNT) através da norma NBR 13904/2003 intitulada "Fios para sutura cirúrgica", que define quais as características os fios absorvíveis e não absorvíveis devem possuir, inclusive a resistência à tração média (ABNT, 2003).

Diferentes calibres e composição de fios de sutura são encontrados no mercado odontológico, sendo os mais utilizados os de Nylon e os de Seda com calibres de 3.0, 4.0 e 5.0. Devido às variadas propriedades entre esses fios, é esperada diferença de resistência à tração entre eles, levando-os a graus de ruptura distintos.

A baixa resistência à tração dos fios de sutura utilizados em Odontologia pode trazer complicações durante os procedimentos cirúrgicos e também para a recuperação pós-operatória dos pacientes. A perda de resistência à tração durante a cicatrização pode dificultar o reparo, consequentemente gerando um ambiente propício para infecções e sangramentos excessivos (Silverstein; Kurtzman; \& Shatz, 2009). Dessa maneira, o conhecimento sobre os diferentes tipos de fios de sutura utilizados nas cirurgias odontológicas e suas propriedades torna-se um importante requisito para os cirurgiões-dentistas pois, no momento da escolha, ele deve selecionar o fio que melhor manterá sua resistência até o final da cicatrização da ferida (Dunn, 2004). 
O presente estudo teve por objetivo avaliar a resistência à tração e deformação dos fios de sutura mais utilizados nas cirurgias odontológicas, por meio dos ensaios de tração, comparando-se os resultados obtidos entre diferentes grupos alocados de acordo com o tipo de material do fio e calibre.

\section{Metodologia}

\subsection{Delineamento experimental}

Este estudo tratou-se de uma pesquisa aplicada, bibliográfica, experimental, descritiva, exploratória, de abordagem quantitativa, com tabulação e análise sistemática de dados (Estrela,2018). A pesquisa foi realizada no Laboratório de Resistência dos Materiais do Centro Universitário de Patos de Minas (UNIPAM). A amostra desse experimento foi constituída de 25 fios de suturas que foram divididos igualmente em cinco grupos experimentais da seguinte forma: G1 - fio de sutura de Nylon 3.0; G2 - fio de sutura de Nylon 4.0; G3 - fio de sutura de Nylon 5.0; G4 - fio de sutura de Seda 3.0; G5 - fio de sutura de Seda 4.0. O fio de Seda 5.0 não foi incluso por seu uso não ser comum em cirurgias odontológicas.

\subsection{Análise da resistência à tração}

A avaliação quantitativa da resistência à tração dos fios de sutura foi realizada por meio de uma prensa universal da marca EMIC com sistema operacional INSTRON. A prensa possui carga máxima de $200 \mathrm{kN}$ para ensaios de tração. Prévia calibragem foi realizada através do sistema, inserindo a espessura dos fios de cada grupo. A análise da resistência à tração gerou um tipo de variável cardinal que foi analisada, por meio da comparação dos grupos, utilizando-se estatística analítica. Para que a prensa universal conseguisse captar os fios de sutura, se fez necessário confeccionar uma adaptação padrão para preensão das extremidades dos fios.

\subsection{Análise estatística}

As variáveis cardinais geradas pelas análises de força e deformação foram testadas quanto a seus padrões de distribuições. Para tal, o teste de normalidade de Lilliefors foi utilizado devido ao número de amostras alocadas em cada grupo. Diante da ausência de normalidade para as variáveis cardinais estudadas, o teste estatístico Kruskal-Wallis foi utilizado para comparar força e deformação dos corpos de prova (Seda 3.0, Seda 4.0, Nylon 3.0, Nylon 4.0 e Nylon 5.0). Para detectar diferenças entre os grupos, o teste de Post Hoc Dunn foi utilizado. Diante da ausência de normalidade das variáveis cardinais geradas, para os corpos de prova cujos grupos experimentais foram compostos por fios de Nylon 3.0, Nylon 4.0 e Nylon 5.0, o teste estatístico Kruskal-Wallis foi utilizado. Diante da ausência de normalidade das variáveis cardinais geradas, para os corpos de prova cujos grupos experimentais foram compostos por fios de Seda 3.0 e Seda 4.0, o teste estatístico não paramétrico Mann-Whitney foi utilizado para comparar esses dois grupos.

Os dados foram tabulados no programa Excel e analisadas por meio do software Bioestat versão 5.3 (Belém, Pará Brasil). O nível de significância estabelecido foi de $5 \%(\alpha=0,05)$. O poder do estudo foi calibrado em $95 \%$ (Beta). Os gráficos foram gerados no software GraphPad Prism (San Diego, Califórnia - USA).

\section{Resultados}

Este estudo laboratorial experimental permitiu a observação, por meio de uma análise quantitativa, dos seguintes resultados apresentados nas tabelas 1 e 2 : 
Tabela 1: Resultados de força de resistência à tração $(\mathrm{N})$ para os grupos testados.

\begin{tabular}{cccccc}
\hline Corpo de Prova & Seda 3.0 & Seda 4.0 & Nylon 3.0 & Nylon 4.0 & Nylon 5.0 \\
\hline 01 & 13,8 & 13,8 & 27,7 & 13,8 & 13,8 \\
02 & 13,8 & 13,8 & 34,6 & 13,8 & 20,8 \\
03 & 13,8 & 13,8 & 27,7 & 20,8 & 13,8 \\
04 & 20,8 & 6,9 & 27,7 & 20,8 & 13,8 \\
05 & 20,8 & 13,8 & 27,7 & 20,8 & 13,8 \\
\hline
\end{tabular}

Fonte: Autores.

De acordo com os resultados encontrados para variável força, disponíveis na Tabela 1, o grupo Nylon 3.0 apresentou os maiores resultados. Tal grupo e se mostrou o mais resistente entre todos os grupos testados para o parâmetro avaliado. Já o grupo Seda 4.0 apresentou os resultados mais baixos, conferindo-lhe uma menor resistência à tração dentre os grupos.

Tabela 2: Resultados de deformação (mm) para os grupos testados.

\begin{tabular}{llllll}
\hline Corpo de Prova & Seda 3.0 & Seda 4.0 & Nylon 3.0 & Nylon 4.0 & Nylon 5.0 \\
\hline 01 & 8,1 & 7,7 & 43,9 & 26,9 & 37,9 \\
02 & 9,6 & 10,2 & 31,4 & 29,9 & 46,4 \\
03 & 12,6 & 11,1 & 41,9 & 35,1 & 33,2 \\
04 & 14,0 & 2,9 & 40,4 & 36,1 & 32,0 \\
05 & 15,0 & 9,6 & 45,3 & 40,1 & 43,5 \\
\hline
\end{tabular}

Fonte: Autores.

De acordo com os resultados disponíveis na tabela 2, foi possível perceber que, em se tratando da variável deformação, existe uma ampla variação entre os corpos de prova e entre os grupos. Ainda assim, foi possível verificar que o grupo Nylon 3.0 foi o mais resistente a deformação, enquanto o grupo Seda 4.0 se mostrou o menos resistente.

Inicialmente, os cinco grupos foram comparados quanto à força de resistência à tração e deformação. Em relação à força, foi observada uma diferença estatística $(\mathrm{p}<0,05)$ para o grupo Nylon 3.0 quando comparado ao Seda 4.0 e ao Nylon 5.0 , conforme representação gráfica abaixo (Gráfico 1).

Gráfico 1: Diferença estatística encontrada por meio do teste estatístico KrusKal-Wallis ( $\mathrm{p}<0,05)$ :

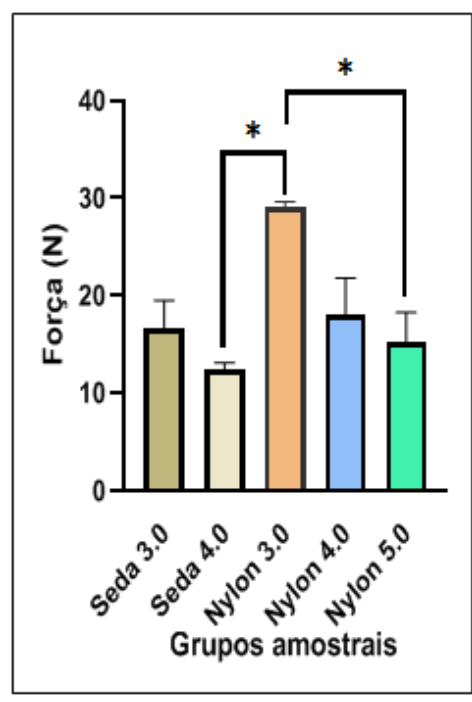

Legenda: *: presença de diferença estatística. Fonte: Autores. 
Para a variável deformação foi encontrada uma diferença estatística $(\mathrm{p}<0,05)$ para o grupo Nylon 3.0 quando comparado com o grupo Seda 3.0 e com o grupo Seda 4.0. O grupo Nylon 5.0 também apresentou uma diferença estatisticamente significante em relação ao grupo Seda 4.0 (Gráfico 2).

Gráfico 2: Diferença estatística encontrada por meio do teste estatístico KrusKal-Wallis ( $\mathrm{p}<0,05)$ :

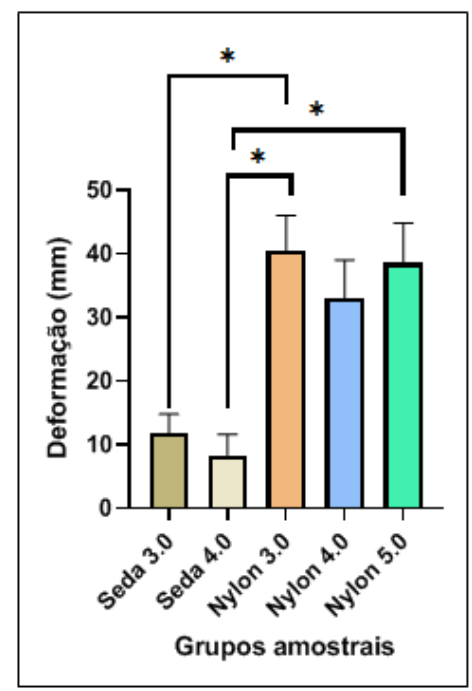

Legenda: *: presença de diferença estatística. Fonte: Autores.

Os grupos também foram comparados estatisticamente conforme o calibre dos fios de acordo com o tipo de material avaliado. Dessa forma, os grupos Nylon 3.0, Nylon 4.0 e Nylon 5.0 foram comparados pelo teste de KrusKal-Wallis e os grupos Seda 3.0 e Seda 4.0 foram comparados pelo teste de Mann Whitney ( $p<0,05$ (Gráfico 3)).

Para a variável força, levando em consideração apenas os grupos compostos pelo material Nylon, foi observado que o grupo Nylon 3.0 e o grupo Nylon 5.0 apresentaram diferença estatisticamente significante (Gráfico 3).

Gráfico 3: Diferença estatística encontrada por meio do teste estatístico KrusKal-Wallis $(\mathrm{p}<0,05)$ :

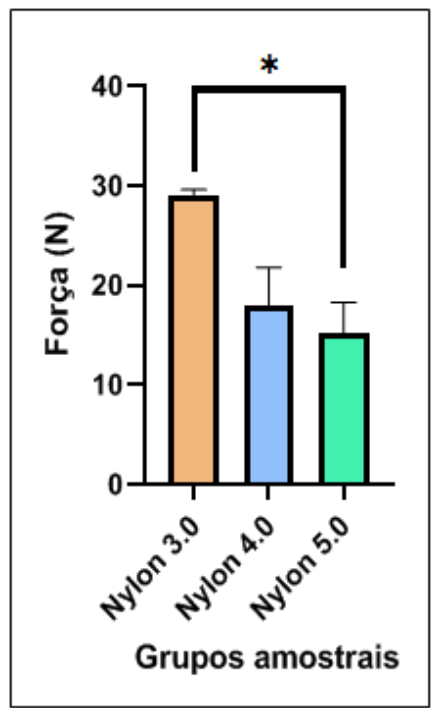

Legenda: *: presença de diferença estatística. Fonte: Autores. 
Para o parâmetro deformação, os grupos não diferiram estatisticamente (Gráfico 4).

Gráfico 4: Nenhuma diferença estatística encontrada por meio do teste estatístico KrusKal-Wallis $(p>0,05)$ :

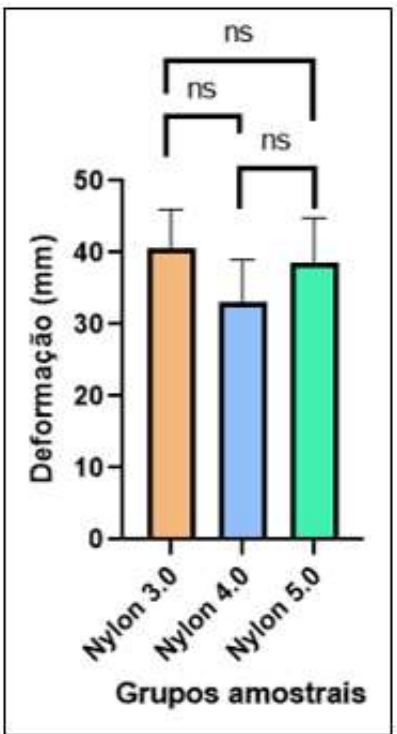

Legenda: ns: não significante ( $\mathrm{p}>0,05)$. Fonte: Autores.

Comparando-se os dois grupos compostos por fios de seda, não foram observadas diferenças estatísticas significantes para as variáveis geradas pela avalição dos parâmetros força e deformação.

Gráfico 5 e 6: Nenhuma diferença estatística encontrada por meio do teste estatístico KrusKal-Wallis (p > 0,05):
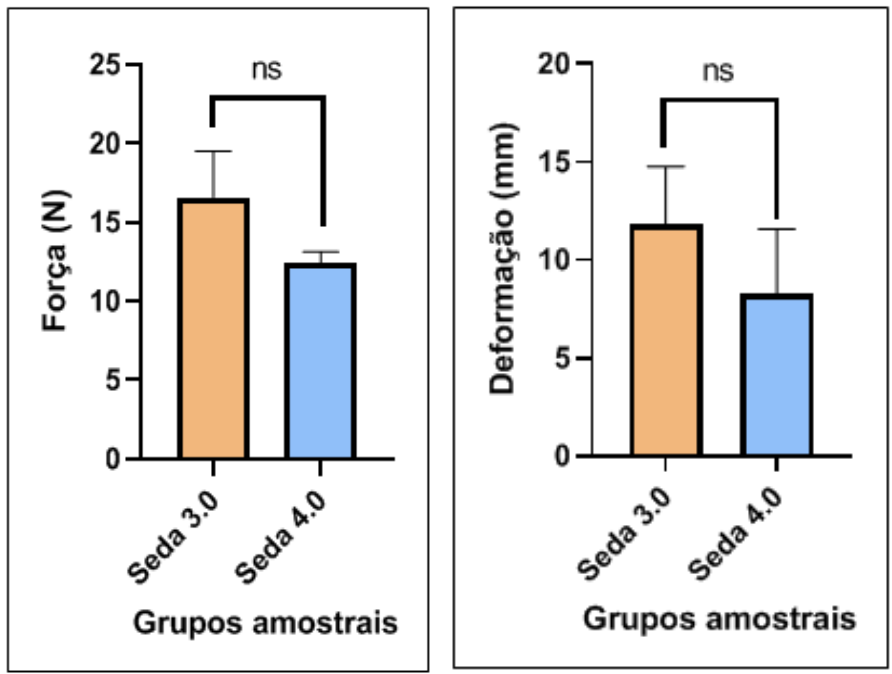

Legenda: ns: não significante ( $\mathrm{p}>0,05)$. Fonte: Autores. 


\section{Discussão}

Durante as cirurgias odontológicas, o profissional pode lançar mão de várias ferramentas que irão auxiliar no fechamento das feridas, suportando as tensões funcionais até que aconteça correta reparação e fechamento do leito, o que influencia diretamente no sucesso e nos bons resultados do procedimento (Burkhardt; \& Lang, 2015; Kurtzman, 2005). A adequada reparação depende principalmente da formação e da estabilização do coágulo sanguíneo, o que pode interferir, também, na tensão funcional da ferida (Wikesjo; Crigger; \& Nilveus, 2015; Gabrielli et al., 2001). Dentre os diversos materiais disponíveis no mercado para o fechamento cirúrgico das feridas, os fios de sutura são os mais utilizados (Kim et al., 2007). Este estudo teve por objetivo avaliar a resistência à tração e deformação dos fios de sutura mais utilizados em odontologia. Dentre os resultados deste trabalho foi possível a observação de diferenças entre os grupos avaliados para as duas grandezas: resistência à tração e deformação, tendo-se percebido diferenças significantes para o grupo Nylon calibre 3.0 frente a outros grupos.

O cirurgião-dentista, em sua rotina de trabalho, pode apresentar preferência por certos tipos de fios de sutura, baseandose em sua habilidade e experiência de trabalho. Vários fatores podem levar a essa escolha, como área de especialização, conhecimento acerca da reparação e fechamento de feridas, das estruturas bucais, e de variantes relacionadas ao paciente (Dunn, 2004; Turker et al, 2010). Além disso, as condições para escolha do fio acompanham o tipo de tecido a ser suturado e a natureza do procedimento. Para essa escolha, é necessário ainda, compreender que as qualidades desejadas para um fio de sutura incluem a facilidade e a resistência no manuseio, deslizamento mínimo, segurança do nó, biocompatibilidade e resistência à tração apropriada ao uso (Akifuddin, 2004; Alves et al,2017; Silverstein, 2005). A técnica de sutura e a seleção do fio também devem levar em consideração esses requisitos, pois nenhum material apresentará todas essas características, sendo função do cirurgiãodentista avaliar e selecionar o fio mais indicado (Kim et al., 2007; Silverstein; Kurtzman; \& Shatz, 2009).

A resistência à tração é uma característica importante para os fios de sutura, e é definida pela United States Pharmacopeia (USP) como quantidade de força necessária para que haja a ruptura do fio dividida por sua área transversal. A resistência efetiva à tração é uma medida adicional para calcular a resistência de fios de sutura que tenham nós atados. Essa resistência varia de acordo com as propriedades de cada material do fio e de acordo com algumas interferências, como danos causados pelos instrumentais, absorção de fluidos bucais, calibre e presença de nós (Bennet, 1988). Além disso, a tração do tecido a ser suturado define qual o valor da resistência à tração que o fio deverá ter, pois estes fios devem se apresentar tão fortes quanto à força de tensão do tecido, mas não necessariamente esse valor precisa ser superior (Dunn, 2004).

Os fios de sutura podem ser classificados quanto a sua estrutura, degradação e composição, características estas que, juntamente ao seu diâmetro, conferem maior ou menor resistência à tração dos fios de sutura. Em relação à estrutura, os fios de sutura podem se apresentar como monofilamentados ou multifilamentados. Quanto à degradação, os fios de sutura são classificados em absorvíveis e não absorvíveis. Por fim, quando se trata de composição, os fios de sutura podem ser divididos em naturais ou sintéticos (Moy; Lee; \& Zalkka, 1991; Greenwald, 1994).

Considerando a rotina clínica do cirurgião dentista, os fios de sutura escolhidos para esse experimento foram aqueles que são mais utilizados durante as cirurgias odontológicas. Foram selecionados 25 fios de sutura, todos eles não absorvíveis, os quais foram divididos em dois grandes grupos, de acordo com o material que os compõe, sendo nylon e seda. Posteriormente os fios foram separados de acordo com o calibre que apresentavam, sendo 3.0, 4.0 e 5.0. Para o grupo dos fios de seda, o calibre 5.0 não foi selecionado, pois não é de uso comum nas cirurgias odontológicas.

Os fios de sutura compostos por Seda são multifilamentados e não absorvíveis, e devido à maciez e flexibilidade são bastante utilizados, pois essas características conferem facilidade de manuseio. Porém, apresentam mínima resistência à tração, sendo um dos fios mais frágeis disponíveis no mercado (Tajirian; \& Goldberg, 2010). Essa informação vai de acordo os resultados obtidos nesse experimento (Tabela 1), pois em relação à força os fios de seda 3.0 apresentaram uma resistência média de 16,6 N, e os fios 4.0 apresentaram resistência média de 12,42N. Já os fios de Nylon podem ser multifilamentados, raramente 
utilizados, ou monofilamentados, que são utilizados com maior frequência. É um fio não absorvível e pouco flexível, o que lhe confere uma maior dificuldade no manuseio, mas que em contrapartida lhe proporciona uma maior resistência à tração (Tajirian; \& Goldberg, 2010). Neste experimento, foram observadas diferenças na resistência dos fios quando os grupos foram comparados. Os fios de Nylon 3.0 apresentaram resistência média de 29,08 N; os fios de Nylon 4.0 apresentaram resistência média de 18 N, e os fios de Nylon 5.0 apresentaram resistência média de 15,2 N. Embora os resultados obtidos entre alguns grupos sejam próximos, quando analisada a força de resistência à tração aplicada entre eles, uma diferença estatística para o grupo Nylon 3.0 quando comparado ao Seda 4.0 e ao Nylon 5.0 foi percebida.

O calibre do fio de sutura é determinado em milímetros e padronizado pela United States Pharmacopeia (USP). O diâmetro transversal é expresso em zeros, sendo que quanto maior o número de zeros, menor será o diâmetro. Essa característica expressa a resistência à tração que cada fio pode apresentar, grandeza essa que pode variar de acordo com a absorção e composição do fio (Bennet, 1988; Meyer; \& Antonini, 1989). Nas cirurgias odontológicas, os fios de sutura mais utilizados são os com diâmetros 3.0, 4.0 e 5.0, os quais proporcionam bons resultados para a grande maioria dos retalhos mucoperiosteais (Silverstein; Kurtzman; \& Shatz, 2009).

Em relação à força aplicada sobre um fio, por meio desse experimento, pôde-se perceber que o calibre do fio de sutura de fato está diretamente ligado à resistência à tração que o mesmo apresenta e que as informações obtidas no presente trabalho estão de acordo com a literatura. Segundo Dunn (2004), quanto menor o calibre, menor será a resistência à tração do fio. Para os fios de sutura do grupo Nylon, houve uma diferença estatisticamente significante entre os fios de menor calibre, 3.0 que apresentaram resistência média de 29,08 N, e os fios de sutura de calibre 5.0, que obtiveram uma resistência média de 15,2N. Porém, para os diferentes calibres dos fios compostos por seda, não houve diferença estatística significante entre os grupos possivelmente devido a maior fragilidade estrutural do material (Tabela 1).

Em 2003, a Associação Brasileira de Normas Técnicas (ABNT) publicou a norma NBR 13904/2003 intitulada "Fios para sutura cirúrgica", visando a padronização da fabricação dos fios de sutura absorvíveis, não absorvíveis naturais e não absorvíveis sintéticos. De acordo com essa norma a resistência à tração deve ser determinada pelos fabricantes após realizar testes em no mínimo dez fios de sutura com nós atados, sendo que para os fios não absorvíveis deve-se fazer uma média com os resultados obtidos e esses valores não podem ser menores que aqueles determinados pela norma. Os fios de sutura compostos por Nylon e Seda são não absorvíveis e entram na Classe I formada por seda ou monofilamentos de fibras sintéticas (ABNT, 2003). Considerando os valores dispostos na norma, os fios 3.0 devem apresentar uma resistência à tração de no mínimo $9,41 \mathrm{~N}$, os fios 4.0 devem apresentar resistência de $5,89 \mathrm{~N}$, e os fios 5.0 apresentaram resistência mínima de 3,92 N. Os testes com os fios de sutura realizados no presente estudo foram feitos sem a presença de nós atados no comprimento no fio, porém os resultados se mostram satisfatórios, pois os valores obtidos são superiores àqueles determinados pela norma, que considera a presença de nó (Tabela 1).

Resultados de deformação para os grupos testados também foram avaliados no experimento. Dentre as qualidades que o fio deve apresentar, a elasticidade é essencial, pois determina a capacidade de alongamento do fio durante o uso nas cirurgias (Burkhardt; \& Lang, 2015). Com a análise dos resultados, pôde-se perceber que a deformação varia muito entre os corpos de prova, até mesmo dentro de um mesmo grupo. Para o grupo Seda 3-0 a média de deformação foi de 11,86 mm, já para o grupo Seda 4.0 a média obtida foi de $8,3 \mathrm{~mm}$. Em se tratando dos grupos compostos por fios de Nylon, estes se mostraram com uma maior capacidade de deformação. Os fios 3.0 apresentaram deformação média de 40,58 mm, os fios 4-0 apresentaram deformação média de 33,62 mm, e os fios 5.0 apresentam deformação média de 38,6 mm. Portanto, mesmo com a grande variação dos valores, os fios de Nylon suportaram maior deformação (Tabela 2).

O presente estudo teve como limitação o embasamento científico em literaturas anteriores e a reduzida quantidade de estudos sobre o tema. Por isso, é necessário que se façam mais ensaios de mecânica de força, utilizando fios de sutura, para que 
haja maior poder de evidência científica sobre parâmetros mecânicos dos fios de sutura que são utilizados diariamente pelos cirurgiões dentistas.

\section{Conclusão}

Por meio da análise dos dados obtidos nesta pesquisa laboratorial experimental, concluiu-se que em relação à força de resistência á tração e à deformação, os fios de Nylon são mais resistentes à tração do que os fios de Seda; especificamente o grupo Nylon 3.0 frente ao Seda 4.0 para resistência à tração e, especificamente, o grupo Nylon 3.0 frente ao grupo Seda 3.0 e ao Seda 4.0 para a resistência à deformação. O grupo Nylon 5.0, também, diferiu estatisticamente do grupo Seda 4.0 para a grandeza deformação. Quando o parâmetro força de resistência à tração foi avaliado exclusivamente para os fios de Nylon, uma diferença foi percebida entre os fios de menor e maior calibres testados. Quando o parâmetro resistência à deformação foi avaliado exclusivamente para os fios de Nylon, nenhuma diferença entre os grupos foi percebida. Quando o parâmetro força de resistência à tração e resistência à deformação foram avaliados exclusivamente para os fios de Seda, nenhuma diferença entre os grupos foi percebida.

\section{Referências}

Alves, A. P., Sá, M. J. C., Fook, M. V. L., Felipe, G. C., Henrique, F. V., Albuquerque, E. E., Medeiros, L. K. G., \& Alexandre, P. R.S. (2017). Avaliação biomecânica e dimensional do fio de sutura à base de quitosana. Arq. Bras. Med. Vet. Zootec, 896-900.

Associação Brasileira de Normas Técnicas (2003). ABNT NBR 13904: Fios para sutura cirúrgica.

Akifuddin, S. (2014). Review On Sutures in Oral Surgery- An Update. Journal of Advanced Medical and Dental Sciences Research, $201-204$.

Bennett R. G. (1988). Selection of wound closure materials. Journal of the American Academy of Dermatology, 18(4 Pt 1), $619-637$.

Burkhardt, R., \& Lang, NP (2015). Influence of suturing on wound healing. Periodontology 2000, 68 (1), $270-281$.

Dunn, D. L. (2004). Ethicon Wound Closure Manual. Ethicon, INC. a Johnson e Johnson company, 2-40.

Estrela, C. (2018). Metodologia Científica: Ciência, Ensino, Pesquisa. Editora Artes Médicas.

Gabrielli, F., Potenza, C., Puddu, P., Sera, F., Masini, C., \& Abeni, D. (2001). Suture materials and other factors associated with tissue reactivity, infection, and wound dehiscence among plastic surgery outpatients. Plastic and reconstructive surgery, 107(1), 38-45.

Greenwald, D., Shumway, S., Albear, P., \& Gottlieb, L. (1994). Mechanical comparison of 10 suture materials before and after in vivo incubation. The Journal of surgical research, 56(4), 372-377.

Kim, J. C., Lee, Y. K., Lim, B. S., Rhee, S. H., \& Yang, H. C. (2007). Comparison of tensile and knot security properties of surgical sutures. Materials in medicine, 18 (12), 2363-2369.

Kurtzman, G. M., Silverstein, L. H., Shatz, P. C., \& Kurtzman, D. (2005). Suturing for surgical success. Dentistry today, $24(10), 96-103$.

Meyer, R. D., \& Antonini, C. J. (1989). A review of suture materials, Part I. Compendium (Newtown, Pa.), 10(5), 260-265.

Moy, RL, Lee, A., \& Zalka, A. (1991). Commonly used suture materials in skin surgery. Am Fam Physician, 44 (6), $2123-2128$.

Shaw, R. J., Negus, T. W., \& Mellor, T. K. (1996). A prospective clinical evaluation of the longevity of resorbable sutures in oral mucosa. The British journal of oral \& maxillofacial surgery, 34(3), 252-254.SILVERSTEIN, L. H. Essential principles of dental suturing for the implant surgeon. Dent Implantol Update, p. 1-7, 2005.

Silverstein, L. H., \& Kurtzman, G. M. (2005). A review of dental suturing for optimal soft-tissue management. Compendium of continuing education in dentistry (Jamesburg, N.J.: 1995), 26(3), 163-209.

Silverstein, L. H., Kurtzman, G. M., \& Shatz, P. C. (2009). Suturing for optimal soft-tissue management. Journal of Oral Implantology, 82-90.

Tajirian, A. L., \& Goldberg, D. J. (2010). A review of sutures and other skin closure materials. Journal of cosmetic and laser therapy: official publication of the European Society for Laser Dermatology, 12(6), 296-302.

Türker, M., Kılıçoğlu, O., Salduz, A., Bozdağ, E., \& Sünbüloğlu, E. (2011). Loop security and tensile properties of polyblend and traditional suture materials. Knee surgery, sports traumatology, arthroscopy: official journal of the ESSKA, 19(2), $296-302$.

Wikesjö, U. M., Crigger, M., Nilvéus, R., \& Selvig, K. A. (1991). Early healing events at the dentin-connective tissue interface. Light and transmission electron microscopy observations. Journal of periodontology, 62(1), 5-14. 